Scotт, W. J. (1958). J. gen. Microbiol. 19, 624-633

\title{
The Effect of Residual Water on the Survival of Dried Bacteria During Storage
}

\author{
By W. J. SCOTT \\ Commonwealth Scientific and Industrial Research Organization, Division of \\ Food Preservation and Transport, Homebush, New South Wales, Australia
}

SUMMARY: The optimum water activity $\left(a_{w}\right)$ for survival of dried bacteria has been determined by storing the organisms in water-vapour equilibrium with solutions of known $a_{w}$ value. The position of the optimum differed according to the composition of the suspending fluid, and the presence or absence of air in the storage atmosphere. For Staphylococcus aureus and Pseudomonas fluorescens, dried in papain digest and stored in vacuo, survival at $0.07,0.11$ and $0.16 a_{w}$ was somewhat better than at $0.00 a_{w}$ and $0.22 a_{w}$. Survival at 0.33-0.53 $a_{w}$ was much less. For Salmonella neroport dried in the same medium the optimum $a_{w}$ in vacuo was less clearly defined, but was well marked and close to $0 \cdot 2$ when stored in air. S. newport, when stored in vacuo, survived best at $0.22 a_{w}$ after drying in a salts buffer or in dialysed horse serum, but in whole serum or the dialysable serum fraction survival was better at $0.00 a_{w}$. S. nerwport dried from water survived best at $0.00 a_{w}$ in vacuo, but at $0.43 a_{w}$ in air. In the presence of sucrose the effect of $a_{w}$ was relatively small. In the presence of glucose or arabinose survival at $0.00 a_{w}$ was better than at $0.22 a_{w}$, which in turn was much better than at $0.48 a_{w}$. In the presence of all three sugars the differences between results in vacuo and in air were small.

Although it has been known for some time that insufficient drying, or excessive absorption of atmospheric moisture, causes a rapid decrease in the viability of dried bacterial cultures, there is no satisfactory evidence regarding the most suitable degree of residual moisture. It is known from the work of Stamp (1947) and Rhodes (1950) that storage over phosphorus pentoxide is, at least under some conditions, reasonably satisfactory. The need for very low water contents during storage has been emphasized by Proom \& Hemmons (1949), who have advocated a period of secondary drying to make the cultures as dry as possible before sealing the ampoules for storage. This view has been questioned by Fry \& Greaves (1951), who have suggested that the beneficial effects of glucose may have resulted from its ability to retain small amounts of water necessary for survival. Although Fry \& Greaves did not furnish direct evidence in support of this suggestion, Hutton, Hilmoe \& Roberts (1951) were able to demonstrate increased survival of Brucella abortus following a limited resorption of water vapour by the dried cultures. The amount of resorbed water which gave greatest survival was, however, too small to permit its satisfactory determination by direct analysis.

In addition to the difficulty of determining small amounts of water analytically, there is a further limitation that values so obtained apply only to the particular solute mixture in which the organisms are suspended. For instance Hutton et al. (1951) used the suspending fluid of Naylor \& Smith (1946) which has a solids content of some $35 \mathrm{mg} . / \mathrm{ml}$., an amount greatly in excess of the 
dry weight of the bacteria suspended in it. In these circumstances the measured water content of the dried culture cannot be regarded as an estimate of the water content of the bacterial cells. These difficulties and uncertainties have been avoided by storing the cultures under constant known water-vapour tension; the present paper reports some of the results obtained.

\section{METHODS}

Cultures for drying were grown on the surface of brain heart agar, or in broth aerated by shaking, for about $20 \mathrm{hr}$. at $30^{\circ}$. The growth on agar was washed off with a papain digest broth prepared as described by Proom \& Hemmons (1949), but from ox heart instead of horse muscle. The suspension so obtained was, when necessary, divided into samples equal in number to the number of suspending fluids to be used, and centrifuged. The organisms were resuspended in the appropriate fluid to a density of about $10^{10} / \mathrm{ml}$. and $0.2 \mathrm{ml}$. samples dispensed in $88 \times 9 \mathrm{~mm}$. Pyrex test tubes. A small (20-25 mg.) cotton-wool plug was inserted c. $5 \mathrm{~cm}$. from the mouth of each tube. The ampoules were supported in a rack so that each tube was radially mounted about $20^{\circ}$ from horizontal, with its mouth some $2 \mathrm{~cm}$. from the surface of the central condenser which was filled with solid $\mathrm{CO}_{2}$ and ethanol. The apparatus accommodated up to 150 ampoules, and in most experiments 100-120 were dried together. Cooling was purely evaporative and heating was by radiation from the walls of the steel vacuum chamber. When desired, the temperatures of the contents of selected ampoules were measured during drying by means of forty-gauge thermocouples connected to a recording potentiometer. It was found convenient to de-gas the suspensions by evacuation until they had cooled to about $0-2^{\circ}$ before the $\mathrm{CO}_{2}+$ ethanol mixture was added to the condenser. Immediately the condenser was cooled the rate of evaporation increased, and organisms suspended in papain digest broth were promptly cooled from $-30^{\circ}$ to $-35^{\circ}$. With this fluid almost all the drying occurred within the first hour, but drying was continued, nevertheless, for 4 or $5 \mathrm{hr}$. In the presence of some solutes drying took place at higher temperatures and from 3 to $4 \mathrm{hr}$. were needed to remove almost all the water.

At the end of this primary drying the ampoules were removed from the vacuum chamber, and, after inserting a small identifying label on top of the cotton-wool plug, each ampoule was placed inside a $150 \times 15 \mathrm{~mm}$. Pyrex tube for storage at a constant predetermined water activity $\left(a_{w}\right)$. The $a_{w}$ within the larger tube was controlled by placing within it $c .2 \mathrm{ml}$. of various aqueous solutions saturated at $\mathbf{2 5}^{\circ}$, together with a small amount of the appropriate solid phase. For $0.07 a_{w}$ the solute was $\mathrm{NaOH}$, and for this solution the glass surfaces likely to be exposed to it were first coated with a thin layer of solid paraffin.

The solutions used to generate the various values of $a_{w}$ were from those listed by Robinson \& Stokes (1955, Appendix 8. 11) with the addition of calcium bromide, a saturated solution of which was, at $25^{\circ}$, found to be in equilibrium with sulphuric acid of $0.162 a_{w}$. For storage at zero $a_{w} 1-2 \mathrm{~g}$. 
phosphorus pentoxide was placed in the bottom of the larger tube. Contents of the large tubes were protected against absorption of atmospheric moisture by inserting rubber stoppers until the tubes were sealed. For sealing, the larger tube was first drawn out to a neck and this was subsequently sealed with the aid of a cross-fire torch. Unless otherwise indicated the tubes were evacuated before sealing. This was done in groups of six on a manifold connected to a two-stage mechanical pump, the solutions at $a_{w} 0.11$ and above being boiled and the non-condensable gases thereby flushed out with the water vapour. Solutions of saturated $\mathrm{NaOH}$ did not boil easily, and these and the tubes containing $\mathrm{P}_{2} \mathrm{O}_{5}$ were pumped out for at least 60 sec. before the final sealing. When storage in air was desired the tubes were not evacuated before the final sealing. In any one experiment the time for sealing the requisite number of tubes never exceeded $3 \mathrm{hr}$. and was usually between $1 \frac{1}{2}$ and $2 \mathrm{hr}$. Immediately after the completion of sealing, the tubes were stored in the dark inside an insulated cabinet within a room maintained at $25^{\circ}$. Temperature conditions within the cabinet were very steady, the daily fluctuations from the mean not exceeding $\mathbf{0 . 0 5 ^ { \circ }}$. The mean storage temperature was probably within the range $25 \cdot 0 \pm 0 \cdot 2^{\circ}$.

The general procedure has been to allot 5-12 replicate ampoules to each of several $a_{w}$ values for storage and to withdraw single or duplicate ampoules after various storage periods for determination of the viable count. Precautions were taken to avoid bias when ampoules were allotted to the different $a_{w}$ values for storage, and also when tubes were selected for withdrawal from storage.

Very few tubes developed cracks during storage, but care was taken to ensure that only tubes with intact seals were used for viable counts. Tubes were opened by first making a scratch with a tungsten carbide knife and leading a crack around the tube with the aid of a small $(5 \mathrm{~mm}$.) flame. This procedure, which has been used on several thousand tubes, caused a gentle release of the vacuum and rendered unnecessary other precautions against the violent ingress of air. After the outer tube was opened, the label and cotton-wool plug were removed from the small tube and the contents rehydrated with $2 \mathrm{ml}$. of saline. When necessary, further dilutions in saline were prepared, in which case the period of sojourn in the $1 / 10$ dilution was not less than $90 \mathrm{sec}$. Duplicate plates were poured at appropriate decimal dilutions and the results are given as two figure logarithms of the viable count $/ \mathrm{ml}$. of original undried suspension. Owing to the exploratory nature of some of the experiments counts were sometimes appreciably above or below the expected values, and it was occasionally necessary to include estimates based on colony counts outside the range of 20-1000 colonies/plate.

\section{RESULTS}

\section{Storage in papain digest in vacuo}

As a papain digest similar to the one used by Proom \& Hemmons (1949) had been adopted for routine preservation of dried cultures in this laboratory some experiments were designed to determine the optimum $a_{w}$ value for 
storage in this medium. Results for a strain of Staphylococcus aureus stored at eight $a_{w}$ values from 0.00 to 0.53 are shown in Fig. 1 . It is quite clear that, under these conditions, the driest environment did not result in the greatest survival.

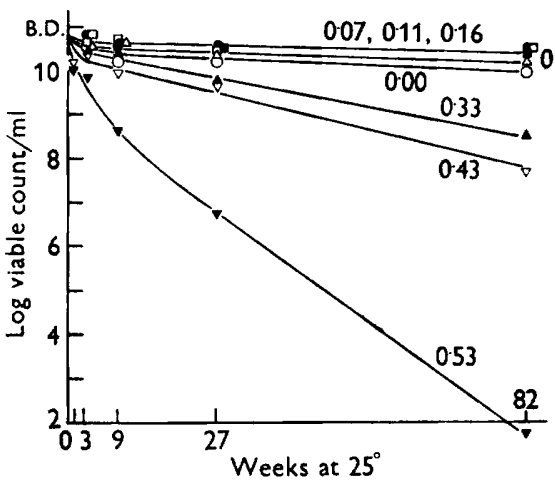

Fig. 1

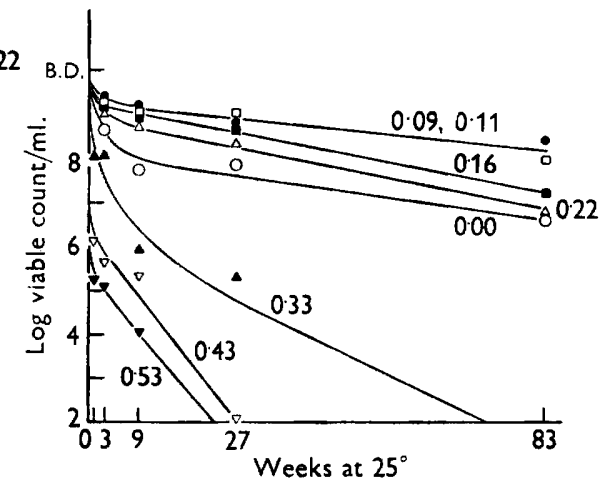

Fig. 2

Fig. 1. Effect of $a_{w}$ value on survival, during storage in vacuo at $25^{\circ}$, of Staphylococcus aureus dried in papain digest broth. Points are means of two estimates based on duplicate ampoules. (B.D. $=$ before drying.)

Fig. 2. Effect of $a_{w}$ value on survival, during storage in vacuo at $25^{\circ}$, of Pseudomonas fluorescens dried in papain digest broth. Points are means of two estimates based on duplicate ampoules.

Results for a second organism, Pseudomonas fluorescens, are shown in Fig. 2. This organism was dried in a portion of the same batch of papain digest as the Staphylococcus aureus, and has shown a greater rate of destruction when stored under the same conditions. Again, the driest conditions did not result in the best survival. Results for Salmonella newport, also dried in the same batch of papain digest, are shown in Fig. 3. For this organism the rate of death showed little variation at several $a_{w}$ values between 0.00 and 0.22 , although survival was markedly less at higher $a_{w}$ values.

The water sorption isotherms at $25^{\circ}$ for suspensions of the above three organisms in papain digest are shown in Fig. 4. These isotherms are for suspensions similar to those used for the experiments in Figs. 1, 2 and 3, and were obtained by the method described previously (Scott, 1953). The total dry matter was $c .50 \mathrm{mg} . / \mathrm{ml}$. of which $c .75 \%$ was from the papain digest itself and $25 \%$ from the organisms. It is clear, for the three suspensions studied, that the equilibrium water contents at the $a_{w}$ values which gave greatest survival were some $3-4 \%$ of the dry weight.

\section{Storage in papain digest in air}

The results of an experiment in which storage in vacuo and in air were compared at six $a_{w}$ values are shown in Fig. 5. The test organism was Salmonella newport. The results for storage in vacuo were very similar to those shown in Fig. 3 for another batch of papain digest medium, dried some months earlier. The replicate tubes stored in air showed a very different response. 
Whereas in vacuo there was little difference between storage at $0 \cdot 00,0 \cdot 11$ and $0.22 a_{w}$, storage in air for 9 or 28 weeks caused much greater mortality at $0.00 a_{w}$ than at several other $a_{w}$ values from $0 \cdot 11$ to $0 \cdot 43$.

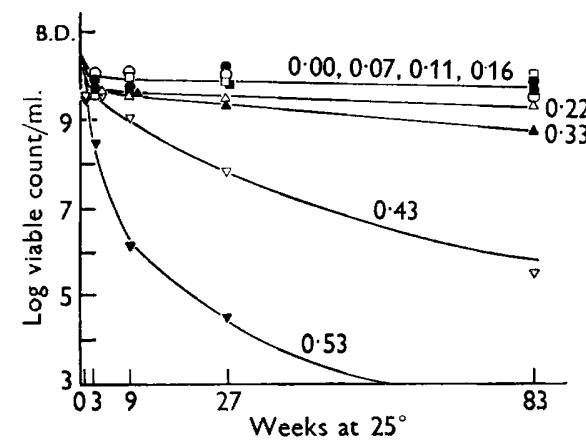

Fig. 3

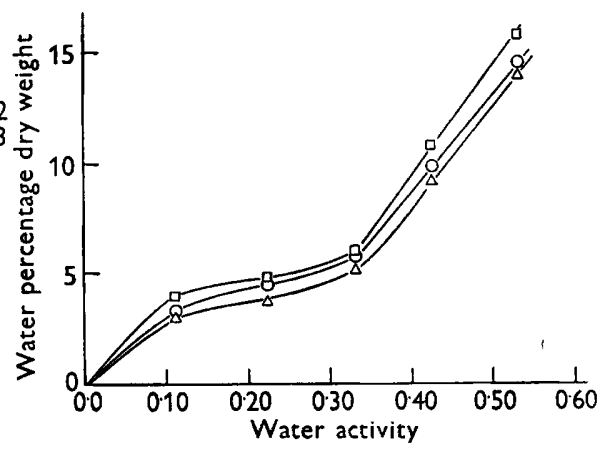

Fig. 4

Fig. 3. Effect of $a_{w}$ value on survival, during storage in vacuo at $25^{\circ}$, of Salmonella nerwport dried in papain digest broth. Points are means of two estimates based on duplicate ampoules.

Fig. 4. Water sorption isotherms at $25^{\circ}$ for three bacteria suspended in papain digest broth. $\square$, Staphylococcus aureus 309 ; $O$, Salmonella newoport 215; $\triangle$, Pseudomonas fuorescens 429 .

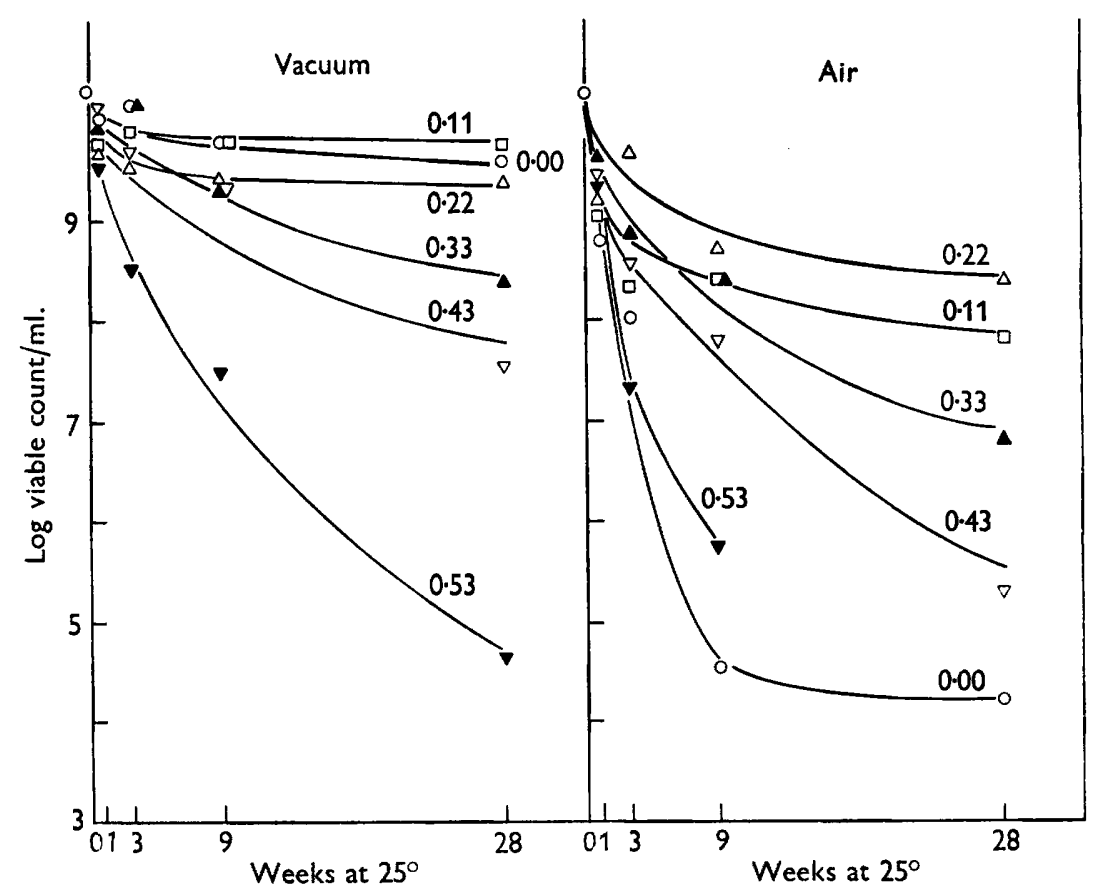

Fig. 5. Effect of $a_{w}$ value on survival, during storage at $25^{\circ}$ in vacuo and in air, of Salmonella newport dried in papain digest broth. Estimates of viable counts based on single tubes only. 
Other experiments have shown that Pseudomonas fuorescens is similarly much more susceptible to very dry conditions when dried in papain digest and stored in air as compared with storage at the same $a_{w}$ value in vacuo.

\section{Storage in serum and serum fractions}

Serum is widely recognized as containing substances which protect dried organisms, and numerous authors have ascribed this to 'protective colloids' (Fry, 1954). The evidence that the protective substances are colloidal is not clear, and does not appear to rest on comparative tests of the dialysable and non-dialysable fractions of serum. Table 1 summarizes the result of an experi-

Table 1. Effect of $a_{w}$ value on survival, during storage in vacuo at $\mathbf{2 5}^{\circ}$, of Salmonella newport dried in various serum fractions

Estimates of viable counts based on single tubes only.

\begin{tabular}{|c|c|c|c|c|c|c|}
\hline \multirow[b]{2}{*}{$\begin{array}{l}\text { Suspending } \\
\text { fluid }\end{array}$} & \multicolumn{2}{|c|}{ Log viable count $/ \mathrm{ml}$. } & \multirow{2}{*}{$\begin{array}{c}\text { Storage } \\
\text { period } \\
\text { (days) }\end{array}$} & \multicolumn{3}{|c|}{$\begin{array}{l}\text { Log viable count } / \mathrm{ml} \text {. } \\
\text { (storage } a_{w} \text { value) }\end{array}$} \\
\hline & $\begin{array}{l}\text { Before } \\
\text { drying }\end{array}$ & $\begin{array}{c}\text { After } \\
\text { drying }\end{array}$ & & $0 \cdot 00$ & $0 \cdot 22$ & 0.43 \\
\hline Salts buffer & $10 \cdot 55$ & $8 \cdot 64$ & $\begin{array}{r}8 \\
22 \\
85 \\
708\end{array}$ & $\begin{array}{l}5 \cdot 51 \\
4 \cdot 65 \\
4 \cdot 60 \\
1 \cdot 70\end{array}$ & $\begin{array}{l}5 \cdot 48 \\
4 \cdot 32 \\
4 \cdot 27 \\
3 \cdot 62\end{array}$ & $\begin{array}{c}4 \cdot 63 \\
4 \cdot 23 \\
3 \cdot 65 \\
-\end{array}$ \\
\hline Horse serum & $10 \cdot 28$ & $9 \cdot 31$ & $\begin{array}{r}8 \\
22 \\
85 \\
708\end{array}$ & $\begin{array}{l}8 \cdot 28 \\
8 \cdot 23 \\
8 \cdot 29 \\
7 \cdot 77\end{array}$ & $\begin{array}{l}8 \cdot 30 \\
7 \cdot 58 \\
8 \cdot 66 \\
6 \cdot 18\end{array}$ & $\begin{array}{c}8 \cdot 14 \\
7 \cdot 75 \\
5 \cdot 72 \\
-\end{array}$ \\
\hline $\begin{array}{l}\text { Dialysable serum } \\
\text { fraction }\end{array}$ & $10 \cdot 40$ & $8 \cdot 33$ & $\begin{array}{r}8 \\
22 \\
85 \\
708\end{array}$ & $\begin{array}{l}7 \cdot 24 \\
7 \cdot 09 \\
7 \cdot 62 \\
7 \cdot 64\end{array}$ & $\begin{array}{l}6 \cdot 87 \\
6 \cdot 84 \\
5 \cdot 16 \\
4 \cdot 90\end{array}$ & $\begin{array}{c}5 \cdot 88 \\
4 \cdot 64 \\
3 \cdot 98 \\
-\end{array}$ \\
\hline $\begin{array}{l}\text { Non-dialysable serum } \\
\text { fraction }\end{array}$ & $10 \cdot 42$ & $8 \cdot 28$ & $\begin{array}{r}8 \\
22 \\
85 \\
708\end{array}$ & $\begin{array}{l}6 \cdot 09 \\
4 \cdot 72 \\
4 \cdot 20 \\
1 \cdot 70\end{array}$ & $\begin{array}{l}6 \cdot 74 \\
5 \cdot 93 \\
6 \cdot 06 \\
4 \cdot 61\end{array}$ & $\begin{array}{c}6 \cdot 11 \\
5 \cdot 33 \\
5 \cdot 32 \\
-\end{array}$ \\
\hline
\end{tabular}

ment in which the storage of Salmonella newport was examined at three $a_{w}$ values in the presence of horse serum, and of its dialysable and non-dialysable fractions as well as in a simple salts buffer approximately isotonic with serum. After storage for 2 years there was greater death at $0.00 a_{w}$ than at $0.22 a_{w}$ in the presence of the salts and in the non-dialysable serum fraction. On the other hand, for the whole serum, and for the dialysable fraction, storage at $0.00 a_{w}$ gave the best survival. It may be seen also that these results have contradicted the proposition that the principal protective components of serum are colloidal.

\section{Storage in the presence of sugars}

In view of the suggestion by Fry \& Greaves (1951) that the beneficial effects of glucose might depend on the retention of some significant amount of residual water some tests were made with bacteria dried in the presence of various sugars. The results of an experiment in which Salmonella newport was 
dried in the presence of 1.1 molal sucrose, glucose and arabinose are shown in Fig. 6. In this particular experiment drying in the presence of each of these sugars was compared with drying in water only. For storage the ampoules were

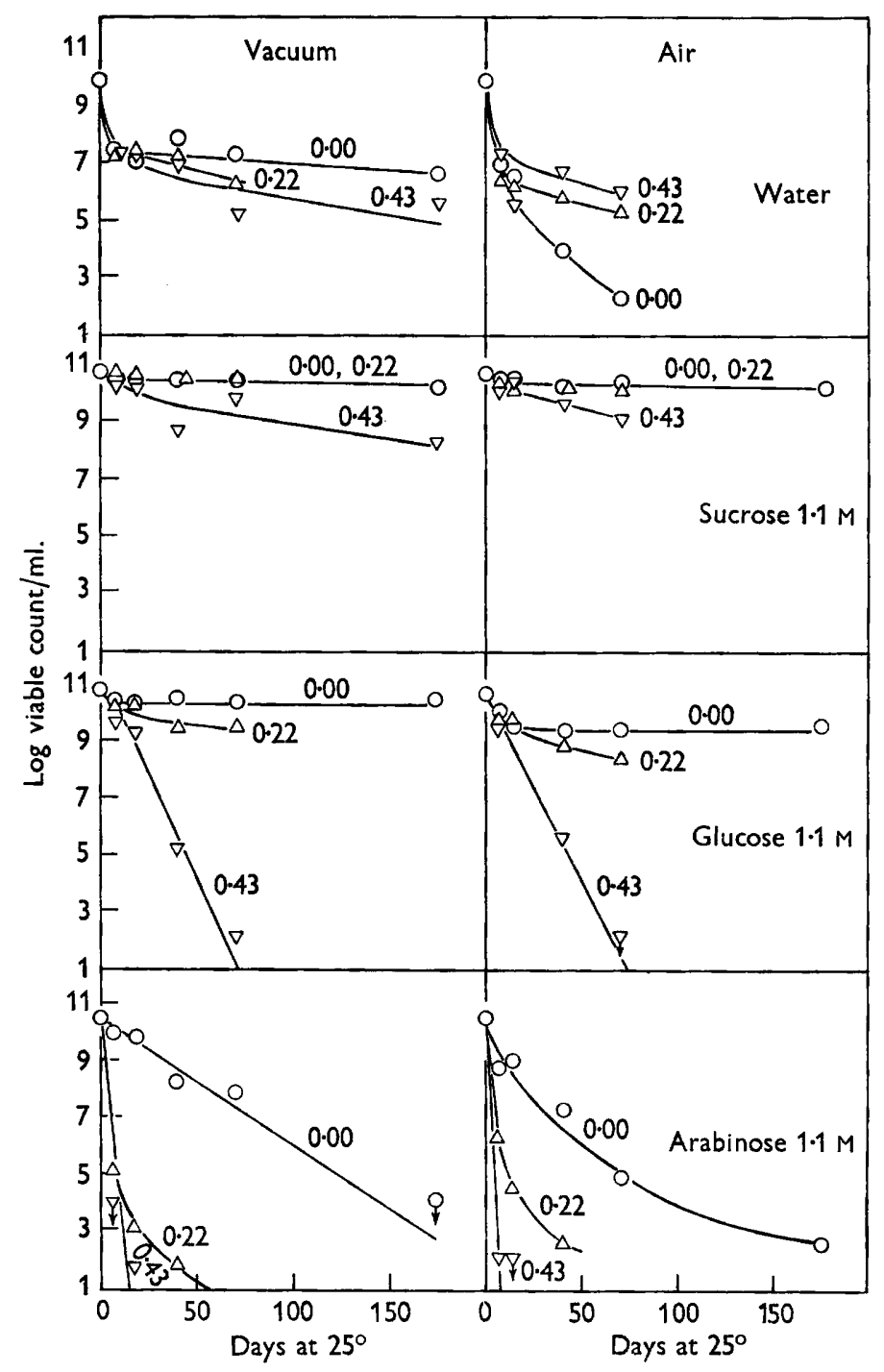

Fig. 6. Effect of $a_{w}$ value on survival, during storage at $25^{\circ}$ in vacuo and in air, of Salmonella newport dried in four different suspending fluids. Estimates of viable counts based on single tubes only.

taken in groups of four, one of each suspending fluid, and these were stored together by sealing within a larger $200 \times 25 \mathrm{~mm}$. tube. This procedure ensured that comparison of the four suspending fluids was not vitiated by minor differences in the storage conditions. 


\section{Residual water and survival of dried bacteria}

From an inspection of the results in Fig. 6 it may be concluded that for Salmonella newport the effect of residual water during storage depends markedly on the type of suspending fluid. For organisms suspended in water only, storage in vacuo has resulted in somewhat better survival at $0.00 a_{w}$ than at 0.22 and $0.43 a_{w}$, but at each $a_{w}$ value there was a large initial rate of death followed by a marked decrease to a much lower rate. For replicate ampoules stored in air the high initial rate of death was again followed by a low rate of death at $0.43 a_{w}$, but at $0.00 a_{w}$ a relatively high rate of death continued beyond the first 2 weeks. For organisms suspended in water, therefore, the effect of air on the relationship between survival and $a_{w}$ was similar to that found for organisms suspended in papain digest (cf. Fig. 4). For organisms suspended in sucrose death during storage was small at 0.00 and $0.22 a_{w}$, and somewhat greater at $0.43 a_{w}$. The high initial rate of death, which was so marked for organisms suspended in water, was no longer evident. The results for storage in vacuo and in air were similar. For cells suspended in glucose solution the changes in viability during storage depended very greatly on $a_{w}$. At $0.00 a_{w}$ storage in vacuo gave virtually the same high survival as in sucrose, although in air the mortality in glucose was somewhat greater. At $0.22 a_{w}$ mortality in the glucose was increased, and at $0.43 a_{w}$ a diminution of about $1 \log$ unit/week was maintained. Although this steady rate was appreciably less than the high initial rate found in the suspension dried from water, it continued without appreciable change until sterility was approached. As a consequence the relative performance of glucose and water was a function of the duration of storage at $0.43 a_{w}$. For example, in air at $0.43 a_{w}$ the viable count in glucose was some 200 times greater than the viable count in water after storage for only 7 days, whereas after 70 days the viable count for the water suspension was 10,000 times greater than in the glucose suspension.

For organisms suspended in arabinose the rate of destruction was much greater than in glucose at all three $a_{w}$. In arabinose death proceeded at a rate which was of the order of $0.25-0.5 \mathrm{log}$ unit/week at $0.00 a_{w}$ and approached $1 \log$ unit/day at $0.43 a_{w}$.

\section{DISCUSSION}

The technique of storing the dried cultures over solutions of known constant $a_{w}$ value undoubtedly caused the $a_{w}$ value of the dried organisms to approach the equilibrium value very closely. The rate at which equilibrium was approached was, however, not determined and there is some uncertainty regarding the average $a_{w}$ value of the organisms during the early part of storage. Observations on the papain digest suspensions suggested, however, that the greater part of the water taken up at 0.43 and $0.53 a_{w}$ was transferred in the first $24 \mathrm{hr}$. of storage. As at lower $a_{w}$ values the amounts of water required to be transferred were much less, it is likely that conditions approaching equilibrium within $c .0 .01 a_{w}$ were realized for most treatments within the first few days of storage. The approach to equilibrium over $\mathrm{P}_{2} \mathrm{O}_{5}$ or with the concentrated sugar solutions may conceivably have been much slower, but it seems unlikely that equilibration has been slow enough to affect the general conclusions. 
The results provide clear evidence about the importance of residual water during storage, without requiring any dependence on analytical determinations of the water present. It is, moreover, likely that the $a_{w}$ value would be a more satisfactory measure of the chemical reactivity of water in dried biological preparations than would estimates of water contents (Scott, 1957). Although the facts are clear enough, their interpretation is by no means simple. The reason for the accelerated rate of death at very low $a_{w}$ values is not obvious, but apparently the removal of the most firmly held water molecules results in some loss of stability especially in the presence of air. In the presence of high concentrations of some sugars the damaging effects of air at low $a_{w}$ values are substantially prevented, but whether this is simply a consequence of the hydrophilic character of the sugar molecule is unknown. It is of interest to find that the optimum $a_{w}$ of $c . \mathbf{0 \cdot 2}$ for the survival in air of Salmonella neroport dried in papain digest is the same as the value reported by Watts (1945) for the survival in air of Streptococcus agalactiae dried in milk. On the other hand, Bullock \& Lightbown (1947) found, with Bacterium lactis aerogenes, no difference in survival at 0.00 and at $0.32 a_{w}$. Storage over $\mathrm{P}_{2} \mathrm{O}_{5}$ was in vacuo, but at $0.32 a_{w}$ the atmosphere was not specified. As they did not store material at any other value of $a_{w}$ their results are not necessarily in conflict with those in the present paper.

The large differences between survival in sucrose, glucose and arabinose which are also a function of $a_{w}$ value have been confirmed in several other experiments. These results suggest that the reducing groups of the latter two sugars might be a significant cause of death during the storage of dried bacteria. Evidence in support of this view has been presented elsewhere (Scott 1958).

The author is greatly indebted to Miss Betty J. Marshall whose skill and care produced the viable counts, and to Mr D. F. Ohye whose attention ensured the con sistent performance of the drying apparatus.

\section{REFERENCES}

Bullock, K. \& Lightвown, J. W. (1947). The inactivation of enzymes and microorganisms in oils and powders. II. The effect of drying on the viability of bacteria, and their thermolability in powders. Quart. J. Pharm. 20, 312.

Fry, R. M. (1954). The preservation of bacteria, p. 215 in Biological Applications of Freezing and Drying. New York: Academic Press.

Fry, R. M. \& Greaves, R. I. N. (1951). The survival of bacteria during and after drying. J. Hyg., Camb. 49, 220.

Hutton, R. S., Hilmoe, R. J. \& Roberts, J. L. (1951). Some physical factors that influence the survival of Brucella abortus during freeze-drying. J. Bact. 61, 309.

NAYloR, H. B. \& Smith, P. A. (1946). Factors affecting the viability of Serratia marcescens during dehydration and storage. J. Bact. 52, 565 .

Proom, H. \& Hemmons, L. M. (1949). The drying and preservation of bacterial cultures. J. gen. Microbiol. 3, 7.

Rhodes, M. (1950). Viability of dried bacterial cultures. J. gen. Microbiol. 4, 450.

Robinson, R. A. \& Stokes, R. H. (1955). Electrolyte Solutions. London: Butterworth. 
Scotr, W. J. (1953). Water relations of Staphylococcus aureus at $30^{\circ}$ C. Aust. J. biol. Sci. 6, 549.

Scott, W. J. (1957). Water relations of food spoilage micro-organisms. Advanc. Food Res. $7,83$.

ScotT, W. J. (1958). A mechanism causing death during storage of dried microorganisms. Symposium on Freezing and Drying. London: Institute of Biology.

STAMP, LoRd (1947). The preservation of bacteria by drying. J. gen. Microbiol. 1, 251.

WATTS, P. S. (1945). The effect of humidity on the survival of dried cultures of Streptococcus agalactiae. J. Path. Bact. 57, 191.

(Received 25 June 1958) 